\title{
Preparation and in-vitro cytotoxicity of zinc oxide nanoparticles against osteoarthritic chondrocytes
}

\author{
Yuan Song and Jie Yang* \\ Department of Orthopaedics, Shanghai Eighth People Hospital, Shanghai 200235, China
}

${ }^{*}$ For correspondence: Email: yangjieyang11@hotmail.com; Tel/Fax: 0086-21-34284588

Received: 7 June 2016

Revised accepted: 21 October 2016

\begin{abstract}
Purpose: To prepare zinc oxide nanoparticles (ZnO NPs) using Piper betle leaf extract by a green synthetic approach, and to evaluate their cytotoxicity towards human osteoarthritic chondrocytes. Methods: $\mathrm{ZnO} N \mathrm{NP}$ were prepared by heating $30 \mathrm{~mL}$ of $0.1 \mathrm{M}$ zinc nitrate $\left(\mathrm{ZnNO}_{3}\right)$ with $10 \mathrm{~mL}$ of Piper betle leaf extract at $90{ }^{\circ} \mathrm{C}$ for $4 \mathrm{~h}$. The ZnO NPs produced were characterized by various techniques, including $x$-ray diffraction (XRD), Fourier transform-infrared spectroscopy (FT-IR), ultraviolet-visible spectroscopy (UV-Vis), energy-dispersive $x$-ray spectroscopy (EDS) and transmission electron microscopy (TEM). The cytotoxicity of the NPs against human osteoarthritic chondrocytes was studied using eosin Y test method.

Results: The change in color of the reaction solution from colorless to pale white within $1 \mathrm{~h}$ indicated the formation of ZnO NPs. FTIR results revealed coating of plant polyphenols on ZnO NPs surface while $X R D$ and EDS demonstrated the hexagonal structure of crystalline ZnO NPs. Dynamic light scattering (DLS) and TEM analyses indicate hexagonal NPs with a mean particle size of $32 \mathrm{~nm}$. In-vitro cytotoxicity data showed that the NPs exhibited concentration-dependent cytotoxicity towards osteoarthritic chondrocytes.

Conclusions: A simple, fast and eco-friendly method for the preparation of ZnO NPs using Piper betle leaf extract is reported here. The NPs exhibit concentration-dependent toxicity towards human osteoarthritic chondrocytes.
\end{abstract}

Keywords: Zinc oxide nanoparticles, Piper betle, Cytotoxicity, Osteoarthritic chondrocytes, Energydispersive $x$-ray spectroscopy, Transmission electron microscopy

Tropical Journal of Pharmaceutical Research is indexed by Science Citation Index (SciSearch), Scopus, International Pharmaceutical Abstract, Chemical Abstracts, Embase, Index Copernicus, EBSCO, African Index Medicus, JournalSeek, Journal Citation Reports/Science Edition, Directory of Open Access Journals (DOAJ), African Journal Online, Bioline International, Open-J-Gate and Pharmacy Abstracts

\section{INTRODUCTION}

There has been increasing research interest in the development of eco- friendly approaches for nanoparticle (NP) synthesis that do not use hazardous reagents in the preparation procedure. Biosynthetic procedures for NP preparation using enzymes, plants and microbes have been considered as feasible, eco-friendly alternative methods to existing physical and chemical approaches [1].
Zinc oxide nanoparticles ( $\mathrm{nnO} N \mathrm{NP}$ ) are an important class of semiconductor material that are of scientific interest because of their wide range of applications in optoelectronics, optics, electronics and biomedicine [2]. Recent studies have demonstrated the use of environmentallyfriendly constituents such as plant extracts, fungi and bacteria for the preparation of ZnO NPs [3]. Among these, plant extracts have been reported to be the most promising materials for obtaining stable colloid of ZnO NPs. Examples of plant materials used in green ZnO NP synthesis from 
aqueous extract of Aloe barbadensis Miller [4], Hibiscus subdariffa [5], Sargassum muticum [6]. These methods offer numerous advantages of eco-friendliness and compatibility for biomedical and pharmaceutical applications where toxic materials are not used for the preparation. Although several plants have already been reported for the preparation of ZnO NPs, there is a need for the development of new green methods that require less time for production of nanoparticles.

This study investigates the use of Piper betle leaf extract for the production of ZnO NPs within 30 min, as well as the evaluation of the in-vitro cytotoxicity of the NPs against osteoarthritic chondrocytes.

\section{EXPERIMENTAL}

\section{Materials}

Zinc nitrate hexahydrate $(\mathrm{Zn}(\mathrm{NO} 3) 2 \cdot 6 \mathrm{H} 2 \mathrm{O})$, dimethyl sulfoxide (DMSO), bovine serum albumin (BSA) and all other solvents were obtained from Sigma-Aldrich Chemical Co., Ltd. (St Louis, MO, USA).

\section{Preparation of Piper betle leaf extract}

Fresh leaves were collected from Piper betle plant close to Shanghai Eighth People's Hospital and cleaned well with deionized water, followed by drying under sunlight. About $5 \mathrm{~g}$ of dried Piper betle leaves were crushed into powder. The powder was then mixed with $30 \mathrm{~mL}$ water and boiled for $15 \mathrm{~min}$ at $90{ }^{\circ} \mathrm{C}$ because high temperature favors the easy solubility of polyphenols in water within short period of time. After cooling, the solution was filtered through cellulose nitrate filter paper to obtain a clear extract, which was stored in a refrigerator.

\section{Synthesis of zinc oxide nanoparticles}

About $10 \mathrm{~mL}$ of Piper betle leaf extract was added to $30 \mathrm{~mL} 0.1 \mathrm{M}$ zinc nitrate solution and stirred at $90{ }^{\circ} \mathrm{C}, 100 \mathrm{rpm}$ for $4 \mathrm{~h}$. The reaction mixture was then centrifuged to obtain a pale white precipitate and washed several times with water followed by ethanol. The product was annealed in a furnace for $1 \mathrm{~h}$ at $200^{\circ} \mathrm{C}$ to obtain ZnO NPs. Control NPs were prepared which did not contain plant extract.

\section{Cell culture}

Osteoarthritic chondrocytes were isolated from fragments of articular cartilage following the procedure described by Altman et al [5]. Briefly, a sequential enzymatic digestion of articular cartilage fragments was carried out for about half an hour with hyaluronidase $(0.1 \%)$ and $1 \mathrm{~h}$ with pronase $(0.5 \%)$, followed by a $1 \mathrm{~h}$ digestion with collagenase $(0.2 \%)$ at a temperature of $37^{\circ} \mathrm{C}$, in a solution containing a mixture of Dulbecco's modified Eagle's medium (DMEM), amphotericin $B$ and penicillin/streptomycin. The cell suspension was then filtered twice using nylon mesh $(70 \mu \mathrm{m})$ and washed by centrifugation at $700 \mathrm{rpm}$ for $10 \mathrm{~min}$. The final suspension contained 90-95 \% viable cells, which was confirmed using the Trypan blue viability test. The chondrocyte primary cultures were then maintained at $37^{\circ} \mathrm{C}$ under $5 \% \mathrm{CO}_{2}$ atmospheric conditions for 2 weeks.

\section{Cytotoxicity evaluation}

Osteoarthritic chondrocytes were initially seeded in 24-well microplates at a concentration of $4 \times$ $10^{4}$ cells/well. Then, $1 \mathrm{~mL}$ of medium was added, containing phenol red with $10 \%$ fetal calf serum, $2 \mathrm{mM}$ glutamine, $200 \mathrm{mg} / \mathrm{mL}$ streptomycin and $200 \mathrm{U} \mathrm{mL}^{-1}$ penicillin. The cells were allowed to become pre-confluent, then exposed to different concentrations $(10,20,40,80$ and $100 \mathrm{ppm})$ of ZnO NPs for about $24 \mathrm{~h}$. A control experiment was conducted in the absence of NPs under similar experimental conditions. After the NP treatment, the cell viability was determined using the eosin $\mathrm{Y}$ test $(0.5 \%)$ in $0.9 \%$ aqueous $\mathrm{NaCl}$ solution. The samples were studied under a light microscope after staining. Stained and unstained cells were considered to be dead and living cells, respectively.

\section{Characterization}

The crystal structure of the $\mathrm{ZnO}$ NPs was analyzed using XRD (D8-Advanced; Bruker, Karlsruhe, Germany) from $20^{\circ}$ to $70^{\circ}$ in $2 \theta$ steps with $\mathrm{Cu} \mathrm{Ka}(\lambda=0.1546 \mathrm{~nm})$ radiation. A UV-Vis (Lambda 950; PerkinElmer, Waltham, MA, USA) spectrophotometer was used to measure the optical absorbance of the NPs. FT-IR studies were conducted to establish the surface capping groups and an FT-IR spectroscopy instrument (JASCO, Tokyo, Japan) was used to analyze the FT-IR spectrum. A high resolution TEM (HRTEM) instrument (JEM 2100; JEOL, Tokyo, Japan) was used to study the morphology of the NPs. The size distribution and zeta potential of the NPs were measured using a nanoparticle analyzer (SZ-100; Horiba Scientific, Edison, NJ, USA). Then, $1 \mathrm{~mL} \mathrm{ZnO}$ colloid was diluted five times with double distilled water and used for dynamic light scattering (DLS) measurements. 


\section{Statistical analysis}

All experiments were performed in triplicate for each concentration used. Absolute values obtained for each treatment were transformed into percentage cell viability. The individual dosedependent cytotoxicity data points are given as the arithmetic mean percentage inhibition compared to the standard control error. Differences between the mean values were analyzed using one-way analysis of variance (ANOVA) at a significance level of $p<0.05$.

\section{RESULTS}

The UV-vis spectrum indicated the formation of ZnO NPs, as shown in Figure 1; the presence of biosynthesized ZnO NPs is indicated by a sharp absorption peak at $335 \mathrm{~nm}$. On the other hand, UV-vis absorption of zinc salt and plant extract showed the optical absorption peaks at 300 and 325 , and $370 \mathrm{~nm}$, respectively. The XRD diffractogram is provided in Figure 2 and contains peaks at $31.7^{\circ}, 34.3^{\circ}, 36.1^{\circ}, 47.4^{\circ}$, $56.4^{\circ}, 62.8^{\circ}, 66.3^{\circ}, 67.8^{\circ}, 68.9^{\circ}, 72.4^{\circ}$ and $76.9^{\circ}$, corresponding to the characteristic indexing planes (100), (002), (101), (102), (110), (103), (200), (112), (201), (004) and (202), respectively, thus indicating the hexagonal crystalline structure of the NPs which is confirmed from standard crystalline database of Joint Committee on Powder Diffraction Standards (JCPDS) with reference number: 01-076-0704.
Similarly, the XRD pattern of the zinc salt showed the presence of sharp diffraction peaks which is characteristic to bulk material thus differentiating from nano zinc oxide, which represented the broad peaks in XRD. On the other hand, XRD pattern of plant extract showed the broad amorphous peak at $26.6^{\circ}$, which is due to the biomolecules of plant extract.

Figure 3 shows the TEM and selected area electron diffraction (SAED) patterns for the $\mathrm{ZnO}$ NPs. Hexagonal NPs with an average size of 30 $\mathrm{nm}$ were observed, and the SAED pattern shows that the NPs were polydispersed and crystalline in nature. Figure 4 shows the energy-dispersive X-ray spectroscopy (EDS) spectrum; peaks corresponding to zinc and oxygen are present, confirming the formation of ZnO NPs.

Figure 5 shows the FT-IR spectrum of the $\mathrm{ZnO}$ NPs. A peak is observed at $500 \mathrm{~cm}^{-1}$, characteristic of the stretching vibrations of the $\mathrm{Zn}-\mathrm{O}$ bond [6]. The bands present around 1,037 $\mathrm{cm}^{-1}$ and $3,400 \mathrm{~cm}^{-1}$ correspond to the symmetric $\mathrm{C}-\mathrm{O}$ stretching and $\mathrm{O}-\mathrm{H}$ group stretching vibrations [7]. The band at $1,650 \mathrm{~cm}^{-1}$ indicates the presence of ketonic functionalities. The surface charge and size distribution of the NPs are shown in Figure 6. The average particle size was $31 \mathrm{~nm}$ and the zeta potential was $-13 \mathrm{mV}$.

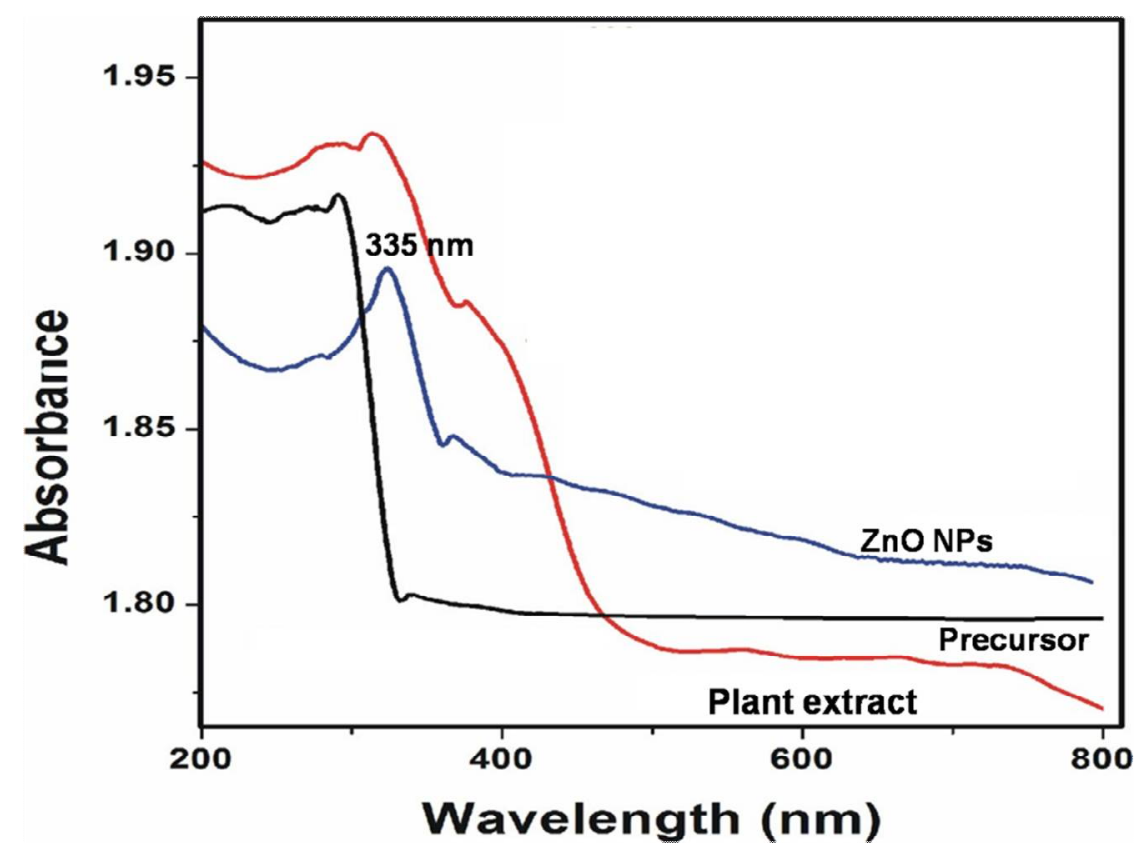

Figure 1: Ultraviolet-visible spectroscopy spectrum of biosynthesized zinc oxide nanoparticles (blue), Zinc salt (black) and plant extract (red) 


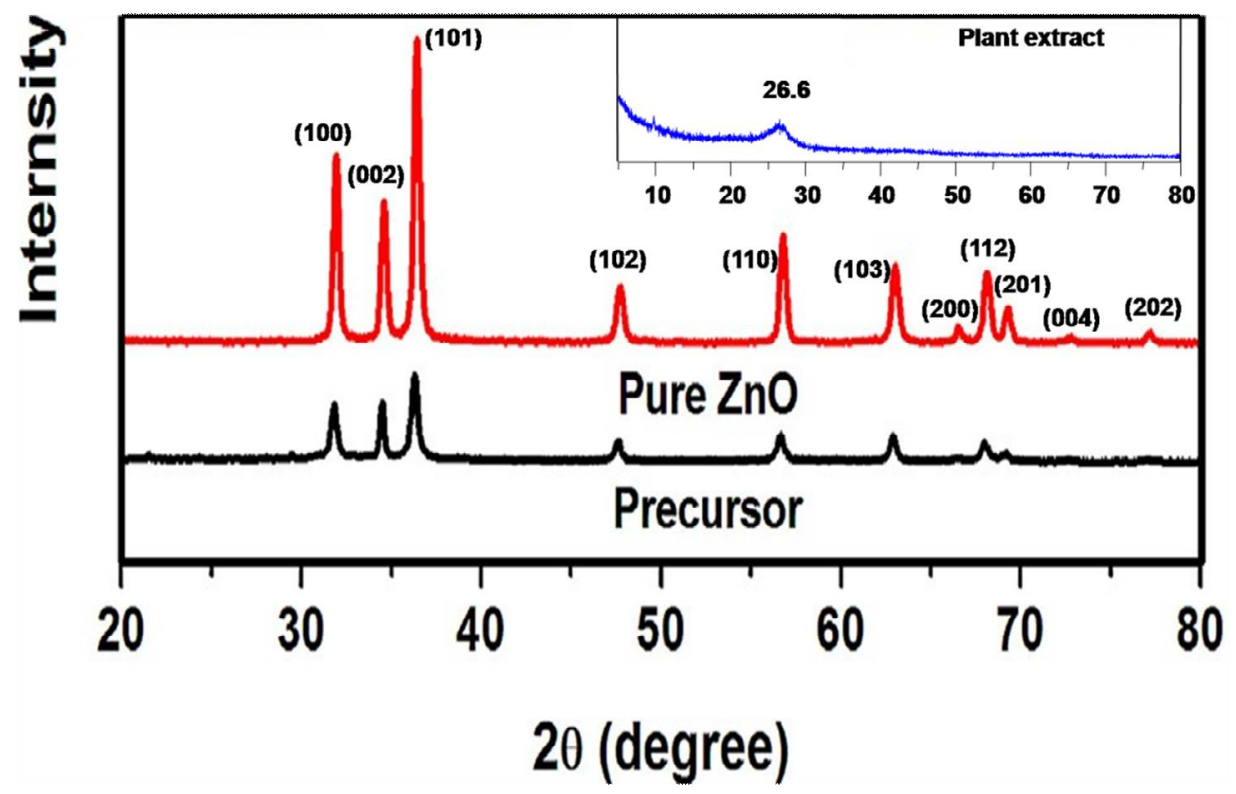

Figure 2: X-ray diffraction patterns of ZnO NPs (red), Zinc salt (black) and plant extract (inset shown)

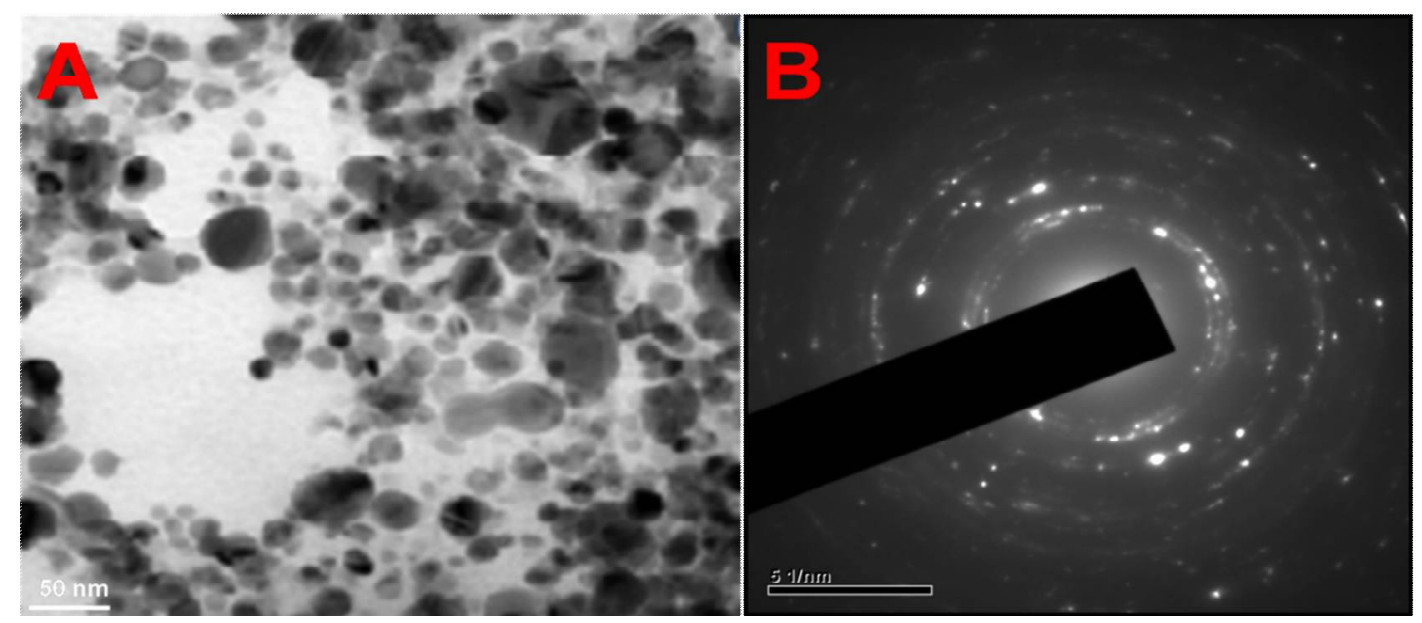

Figure 3: (A) Transmission electron microscopy image (B) Selected area electron diffraction pattern of ZnO NPs

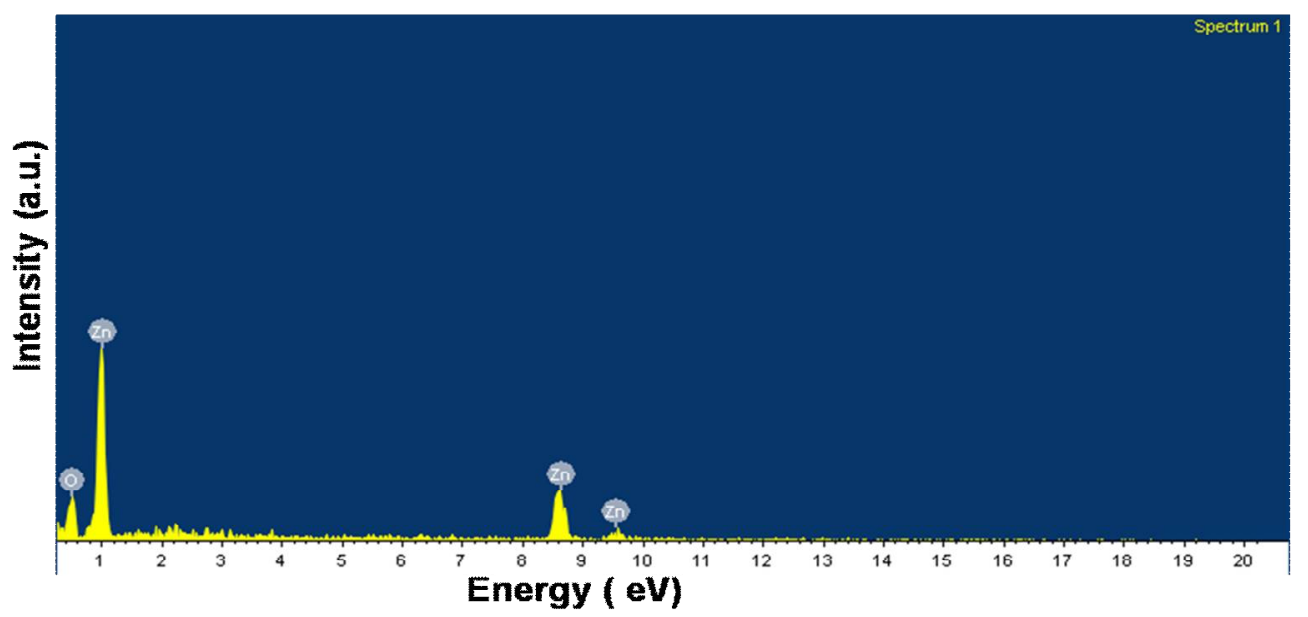

Figure 4: Energy-dispersive X-ray spectroscopy spectrum of biosynthesized ZnO NPs 


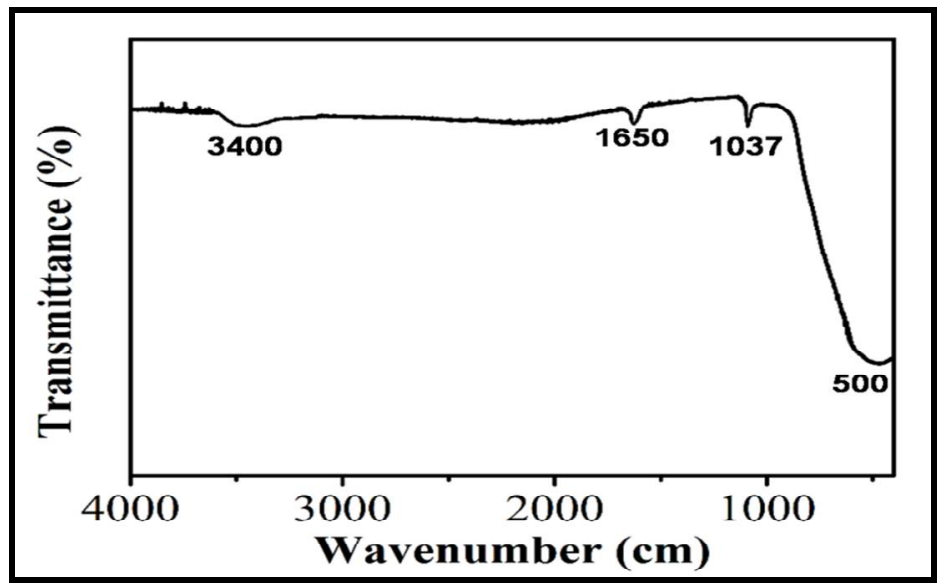

Figure 5: Fourier transform-infrared spectroscopy spectrum of biosynthesized ZnO NPs
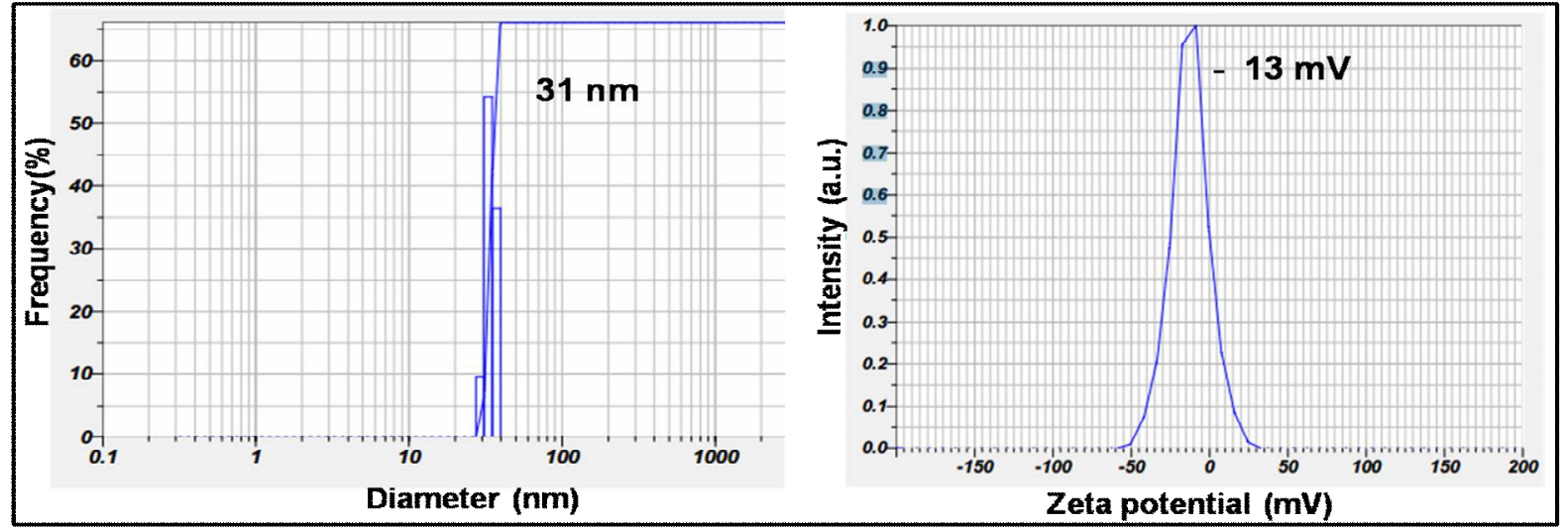

Figure 6: (A) Dynamic light scattering and (B) zeta potential of ZnO NPs

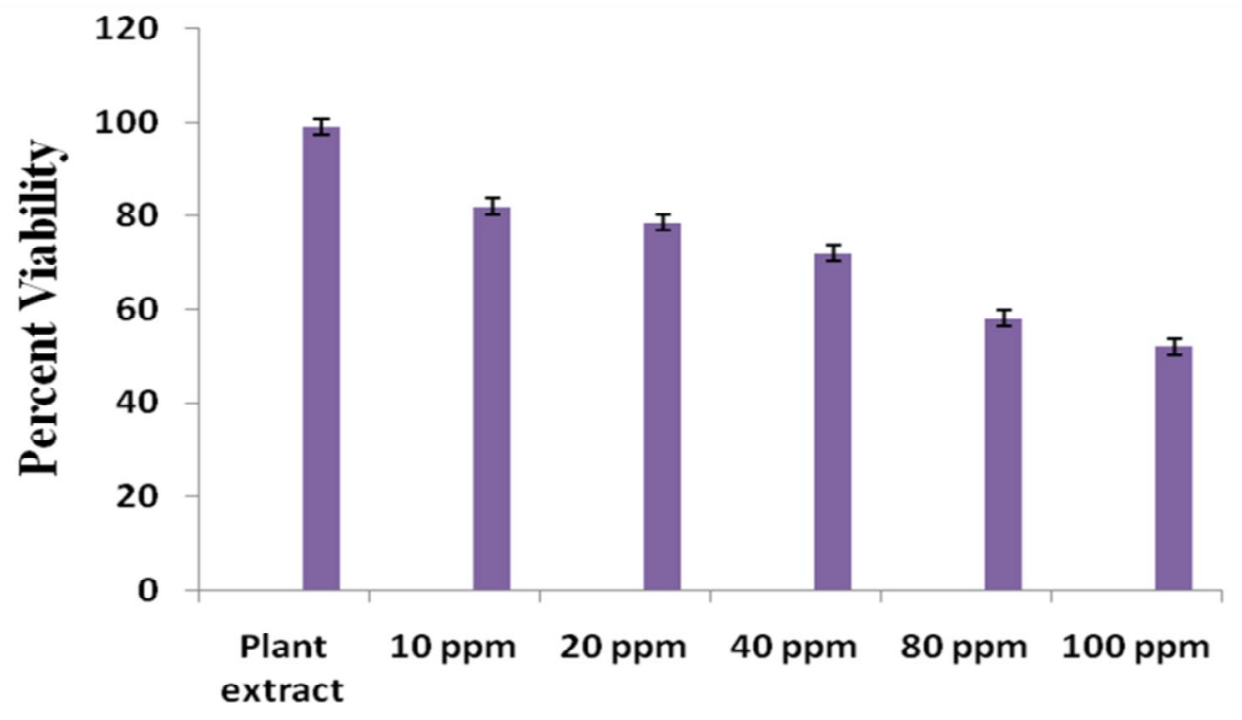

Figure 7: Cell viability of osteoarthritic chondrocytes induced by ZnO NPs

\section{Osteoarthritic chondrocyte viability}

Figure 7 shows the effects of the NPs on the percentage viability of osteoarthritic human chondrocytes. It is found that the cell viability is decreased with increase in the concentration of
$\mathrm{ZnO}$ NPs treated and $82 \%$ cell viability was observed at a ZnO NP concentration of $10 \mathrm{ppm}$, which decreased to $52 \%$ when the concentration increased to $100 \mathrm{ppm}$. The half maximal concentration $\left(\mathrm{IC}_{50}\right)$ value, where $50 \%$ cell viability is observed, was $100 \mathrm{ppm}$. 


\section{DISCUSSION}

Initial identification of $\mathrm{ZnO} \mathrm{NP}$ formation was confirmed by visual color changes during synthesis. The reaction between Piper betle plant leaf extract and $\mathrm{ZnNO}_{3} \cdot 6 \mathrm{H}_{2} \mathrm{O}$ caused a change in the solution from colorless to pale white within 1 $\mathrm{h}$, and the reaction was complete within $4 \mathrm{~h}$ at 80 ${ }^{\circ} \mathrm{C}$, which was faster and cooler than observed in previous studies [8-10]. No color change was observed after 3 days in the control experiment, indicating the importance of Piper betle extract in ZnO NP synthesis.

The XRD diffractogram show the formation of $\mathrm{ZnO}$ NPs. The presence of $\mathrm{x}$-ray diffraction peaks characteristic of $\mathrm{ZnO} N P s$, and the related indexing planes, indicate the hexagonal structure of the synthesized NPs. Furthermore, the crystalline data from the prepared NPs matched standard crystal data (JCPDS NUMBER: 01-0760704). No other diffraction peaks corresponding to impurities were found, indicating that this biosynthetic approach could be employed for synthesis of high-purity NPs. The synthesis of ZnO NPs by Piper betle plant extract was also further confirmed by EDS and TEM analyses. The EDS spectrum showed the presence of zinc and oxygen without any other impurity peaks, indicating the high purity of the synthesized $\mathrm{ZnO}$ NPs.

FT-IR analysis confirmed the surface stabilization of $\mathrm{ZnO}$ NPs with bioconstituents of the plant extract. The existence of bands characteristic of $\mathrm{O}-\mathrm{H}$ and $\mathrm{C}-\mathrm{O}$ bond stretching in the FT-IR spectrum indicated capping of the secondary metabolites of the plant extract on the biosynthesized NPs $[11,12]$. These results are also supported by the negative surface charge of the NPs, which may be due to phenolic functional groups from the plant extract present on NP surfaces. This negative surface charge may generate repulsive forces between NPs, reducing aggregation and resulting in further stability. The negative surface charge of NPs synthesized using green reagents has been discussed in previous studies [13]; from these results, the stabilization of plant polyphenols onto the surface of the prepared $\mathrm{ZnO}$ NPs can be established.

The cytotoxicity of the ZnO NPs at different concentrations was investigated to determine their effects on chondrocytes. The results demonstrate a dose-dependent cytotoxicity similar to that exhibited by other noble metal NPs with different cancer cell lines. For instance, Babu et al [14] demonstrated the concentrationdependent cytotoxicity of gold NPs on human colon and lung cancer cell lines Johnston et al reported that gold nanorods are more toxic than spherical gold NPs, which are biocompatible [15]. This may indicate that the cytotoxicity of NPs depends on their size, shape and surface functionalities. In contrast, the plant extract showed negligible cytotoxicity, indicating that the cytotoxicity in the present method is purely due to the ZnO NPs. However, the prepared NPs showed more than $50 \%$ cell viability even at higher concentrations, indicating their biocompatible nature. Further, the biocompatibility of ZnO NPs makes them suitable for biomedical applications.

\section{CONCLUSION}

A simple, low-cost, eco-friendly method for the preparation of $\mathrm{ZnO}$ NPs using Piper betle leaf extract has been achieved. FT-IR and zeta potential studies demonstrate the stabilization of ZnO NPs with Piper betle extract polyphenols. The Piper betle extract-mediated ZnO NPs showed concentration-dependent cytotoxicity against osteoarthritic chondrocytes.

\section{DECLARATIONS}

\section{Acknowledgement}

The authors acknowledge the help of the Shanghai Eighth People's Hospital in providing funds and laboratory facilities for this research.

\section{Conflict of Interest}

No conflict of interest associated with this work.

\section{Contribution of Authors}

The authors declare that this work was done by the authors named in this article and all liabilities pertaining to claims relating to the content of this article will be borne by them.

\section{Open Access}

This is an Open Access article distributed under the terms of the Creative Commons Attribution License, which permits unrestricted use, distribution, and reproduction in any medium, provided the original work is properly credited.

\section{REFERENCES}

1. Mohanpuria $P$, Rana NK, Yadav SK. Biosynthesis of nanoparticles: technological concepts and future applications. J Nanopart Res 2008; 10: 507-517.

Trop J Pharm Res, November 2016; 15(11): 2326 
2. Srivastava V, Deepak G, Sharma YC. Synthesis, characterization and application of zinc oxide nanoparticles (n-ZnO). Ceram Int 2013; 39: 9803-9808.

3. Sagar BR, Thorat PV. A Review on Preparation, Characterization and Application of Zinc Oxide ( $\mathrm{ZnO})$ Nanoparticles by Green Synthesis Method. Int $J$ of Emerg Tech Adv Eng 2015; 5: 521-524.

4. Sangeetha G, Rajeshwari S, Venckatesh R. Green synthesis of zinc oxide nanoparticles by aloe barbadensis miller leaf extract: Structure and optical properties. Mater res bull 2011; 46: 2560-2566.

5. Bala N, Saha S, Chakraborty M, Maiti M, Das S, Basub $R$, Nandy $P$. Green synthesis of zinc oxide nanoparticles using Hibiscus subdariffa leaf extract: effect of temperature on synthesis, anti-bacterial activity and antidiabetic activity. 2015; 5: 4993-5003.

6. Azizi S, Ahmad MB, Namvar F, Mohamad R. Green biosynthesis and characterization of zinc oxide nanoparticles using brown marine macro alga Sargassum muticum aqueous extract. Mat Lett. 2014; 116: 275-277.

7. Altman $R$, Alarcon $G$, Appelrouth $D$, Bloch $D$, Borestein $D$, Brandt K, Brown C, Cooke TD, Daniel W, Feldman D. The American College of Rheumatology criteria for the classification and reporting of osteoarthritis of thehip. Arthritis Rheum. 1991; 34: 505-514.

8. Rajiv $P$, Rajeshwari S, Venckatesh R. Bio-fabrication of zinc oxide nanoparticles using leaf extract of Parthenium hysterophorus $L$. and its size-dependent antifungal activity against plant fungal pathogens. Spectrochimica Acta A Mol Biomol Spectrosc 2013; 112: 384-387.

9. Barros Gomes Camara R, Silva Costa L, Pereira Fidelis G, Duarte BarretoNobre LT, Dantas-Santos N, Lima Cordeiro S, Santana Santos Pereira Costa M, Guimaraes Alves L, Oliveira Rocha HA. Heterofucans from the brown seaweed canistrocarpuscervicornis with anticoagulant and antioxidant activities. Mar Drugs 2011; 9: 124-138.

10. Jayaseelan C, Rahuman AA, Kirthi AV, Marimuthu S, Santhoshkumar T, Bagavan A, Gaurav K, Karthik L, Rao $K V B$. Novel microbial route to synthesize $\mathrm{ZnO}$ nanoparticles using Aeromonas hydrophila and their activity against pathogenic bacteria and fungi. Spectrochim Acta A 2012; 90: 78-84.

11. Abdul Salam $H$, Sivaraj $R$, Venckatesh R. Green synthesis and characterization of zinc oxide nanoparticles from Ocimum basilicum $L$. var. purpurascens Benth.-Lamiaceae leaf extract. Mater Lett 2014; 131: 16-18.

12. Singh G, Babele PK, Kumar A, Srivastava A, Sinha RP, Tyagi MB. Synthesis of $\mathrm{ZnO}$ nanoparticles using the cell extract of the cyanobacterium, Anabaena strain L31 and its conjugation with UV-B absorbing compound shinorine. J Photo chem Photo biol 2014; 138: 55-62.

13. Kumar K, Kumar M, Kumar HA, Babu M. Green synthesis of size controllable gold nanoparticles. Spectrochim. Acta Mol. Biomol. Spectrosc. 2013; 116: 539-545.

14. Babu M, Kumar M, Raviraj V, Poliraju K, Reddy P. Bioinspired reduced graphene oxide nanosheets using Terminalia chebula seeds extract. Spectrochim. Acta Mol Biomol Spectrosc 2015; 145: 117-124.

15. Hemali $P$, Pooja M, Sumitra $C$. Green synthesis of silver nanoparticles from marigold flower and its synergistic antimicrobial potential. Arab Chem 2015; 8: 732-741.

16. Babu M, Kumar M, Shivendu Rand Nandita D. Diastase assisted green synthesis of size controllable gold nanoparticles. RSC Adv. 2015; 5: 26727-26733.

17. Johnston HJ, Hutchison G, Christensen FM, Peters S, Hankin $S$ and Stone $V$. A review of the in vivo and in vitro toxicity of silver and gold particulates: particle attributes and biological mechanisms responsible for the observed toxicity. Crit Rev Toxicol 2010; 40: 328-346. 